\title{
Minimal invasive oro-dental procedures - recommendations for optimal care in children with haemophilia
}

CS II Andrei KOZMA ${ }^{1,4}$, PhD, MMD, MDHC, CS Emilia URSU², MD, Conf. Roxana OANCEA ${ }^{3}, M D, P h D$, Assist. Prof. Ana Maria Alexandra STANESCU ${ }^{5}, \mathrm{MD}, \mathrm{PhD}$, Prof. Margit SERBAN ${ }^{2,4^{*}}, \mathrm{MD}, \mathrm{PhD}$, Assoc. Prof. Smaranda ARGHIRESCU ${ }^{3}, \mathrm{MD}, \mathrm{PhD}$

1"Alessandrescu-Rusescu" National Institute for Mother and Child Health, Bucharest

2"Louis Turcanu" Children`s Emergency Hospital, Timisoara, Romania 3"Victor Babes" University of Medicine and Pharmacy, Timişoara, Romania

${ }^{4}$ Romanian Academy of Medical Sciences

5"Carol Davila" University of Medicine and Pharmacy, Bucharest

\begin{abstract}
Oral and dental treatments are an essential condition for a good quality of life for hemifiliacs. Hemophilia is a hereditary disease that is manifested in male subjects and consists in lifelong alteration of antihemorrhagic mechanisms. Clinical investigations show that a significant percentage of haemophiliacs are diagnosed with bleeding of the oral and periodontal mucosa during both prosthetic and dental morphology restoration maneuvers. Small dental surgery procedures such as anesthesia, extirpation of dental pulp and other surgical procedures require pre- and postoperative treatment with Factor VIII or factor IX. The authors present steps that are indicated to be performed before, during and after dental treatments that can cause bleedings in the oral cavity. The area and mode of use of alternative or complementary hemostatic therapy is also presented, as well as the precautions required during local anesthesia. In conclusion, it can be said that people with haemophilia or congenital bleeding tendencies are a priority group for dental and oral health care, since bleeding after dental treatment may cause severe or even fatal complications. Maintenance of a healthy mouth and prevention of dental problems is of great importance, not only to quality of life and nutrition, but also to avoid the dangers of surgery.
\end{abstract}

Keywords: haemophilia, dental treatment, antihemorrhagic factors, local anesthetics

Dental and oral health represent an important condition for a good quality of life. To reach it can be a challenging process in persons with haemophilia (1-3).

Haemophilia and related disorders are a group of inherited bleeding disorders characterized by a life-long defect in the clotting mechanism. Haemophilia A and B are defined by their deficiency in Factor VIII and IX, respectively. They are rare diseases with an estimated frequency of $1 / 10,000$ males in haemophilia $A$ and
$1 / 50,000$ males in haemophilia B. They are considered severe when plasma activity - for F VIII or IX is $<1 \mathrm{IU} / \mathrm{dl}$, moderate if it ranges between 1-5 IU/dl and mild if it is between 5-40IU/dl. Clinical investigators, estimating the nature of symptoms which are leading to the diagnosis, reported that $14 \%$ of haemophiliacs and $30 \%$ of cases with mild haemophilia were diagnosed based on a significant oral or dental bleeding $(3,4)$. 
TABLE 1. Average age for tooth eruption

Deciduous (Primary) Teeth

\begin{tabular}{|l|c|c|}
\hline & \multicolumn{2}{|c|}{ Age (in months) } \\
\hline & Upper & Lower \\
\hline 1.Central incisors & $8-13$ & $6-10$ \\
\hline 2.Lateral incisors & $8-13$ & $10-16$ \\
\hline 3.Canines (cuspids) & $16-23$ & $16-23$ \\
\hline 4.First molars & $13-19$ & $13-19$ \\
\hline 5.Second molars & $25-33$ & $23-31$ \\
\hline
\end{tabular}

Permanent Teeth

\begin{tabular}{|l|c|c|}
\hline & \multicolumn{2}{|c|}{ Age (in years) } \\
\hline & Upper & Lower \\
\hline 1.Central incisors & $7-8$ & $6-7$ \\
\hline 2.Lateral incisors & $8-9$ & $7-8$ \\
\hline 3.Canines (cuspids) & $11-12$ & $9-10$ \\
\hline 4.First premolars (bicuspids) & $10-11$ & $10-12$ \\
\hline 5.Second premolars (bicuspids) & $10-12$ & $11-12$ \\
\hline 6.First molars & $6-7$ & $6-7$ \\
\hline 7.Second molars & $12-13$ & $11-13$ \\
\hline 8.Third molars & $17-21$ & $17-21$ \\
\hline
\end{tabular}

Physiological events (decidual or permanent tooth eruption, mobile tooth roots and naturally falling out of decidual tooth) (Tab.1), but moreover medical interventions (treatment of dental caries or of periodontal damage, dental plaque correction) or invasive procedures (tooth extraction, suturing of wounds or incisions, local anaestesia, fixed or removable orthodontic appliances, endodontic pulpectomy, anesthesia with inferior alveolar dental block or lingual infiltration) can cause bleedings, that persist for days or weeks, generating life - threatening complications, which can be stopped only with specific, disease - adapted measures. They can occur even in asymptomatic haemophiliacs with moderate or mild disease $(4,5)$.

Taking all these into consideration, it is obvious that successful protocols can only be the result of cooperation between dentist and hematologist, in frame of a comprehensive care team and center. The purpose of such guidelines is the safety of the group of patients, vulnerable from the point of view of their hemostasis, presenting the risky burden of very rare disorders, with unmet and not generally known needs (Table 2 and Table 3 ).
TABLE 2. The need of hemostatic replacement therapy

\begin{tabular}{|l|l|}
\hline \multicolumn{2}{|c|}{ LOCAL ANESTHETIC TECHNIQUES } \\
\hline NO HEMOSTATIC COVER & HEMOSTATIC COVER \\
REQUIRED & REQUIRED \\
\hline - Bucal infiltration & $\bullet$ Inferior dental (ID) \\
$\bullet$ Intra-papillary injections & block \\
$\bullet$ Intra-ligamentary injections & $\bullet$ Lingual infiltration \\
\hline
\end{tabular}

In the following we will present some recommendations to be respected in our medical activity (6-9).

\section{First Steps - before stomatological treatment}

- informing the dentist that the patient has haemophilia before beginning any procedure

- people with bleeding disorders need close cooperation between their physician and their dentist to receive safe, comprehensive dental care

- in order to help the dentist for planing a correct course of treatment, it is important to provide the following information

- the type and severity of hemophilia

- the medications used

- whether pre-treatment with factor concentrate, nasal desmopressin or an antifibrinolytic agent (tranexamic acid or epsilon amino caproic acid) is required

- contact information about the Haemophilia Treatment Center

- whether there are:

- inhibitors anti-FVIII or FIX

- infectious diseases, such as hepatitis, HIV infection

- previous joint replacement

- venous access device (port)

- dental appointments of children with bleeding disorders, as well as education in preventive dentistry for children and caregivers, should be started when the baby teeth begin to erupt

- comprehensive dental assessment is needed at the age of about 12 or 13 , to plan for the future and to decide how best to forestall difficulties resulting from overcrowding or misplaced third molars or other teeth

TABLE 3. Suggested plasma factor peak level and duration of administration of coagulation factor concentrates in minor invasive interventions

\begin{tabular}{|l|c|c|c|c|c|c|}
\hline & \multicolumn{3}{|c|}{ Haemophilia A } & \multicolumn{3}{c|}{ Haemophilia B } \\
\hline Type of bleeding & $\begin{array}{c}\text { Desired } \\
\text { level UI/kg }\end{array}$ & $\begin{array}{c}\text { Factor } \\
\text { dosage UI/kg }\end{array}$ & $\begin{array}{c}\text { Duration } \\
\text { days }\end{array}$ & $\begin{array}{c}\text { Desired } \\
\text { level UI/dl }\end{array}$ & $\begin{array}{c}\text { Factor } \\
\text { dosage UI/kg }\end{array}$ & $\begin{array}{c}\text { Duration } \\
\text { days }\end{array}$ \\
\hline Pre-operative & $50-100$ & $25-50$ & 1 & $50-100$ & $50-100$ & \\
\hline Post-operative & $30-80$ & $15-40$ & $1-5$ & $30-80$ & $30-80$ & $1-5$ \\
\hline
\end{tabular}


- for those with severe haemophilia, factor replacement is necessary before scaling, surgery or regional block injections. For example, a dose of 50 international units per kilogram of body weight (IU/ kg) of factor VIII is desirable before a tooth extraction in a person with haemophilia $A$; in haemophilia $\mathrm{B}$, a dose of $100 \mathrm{IU} / \mathrm{kg}$ of factor IX is required (Table 3)

\section{General tips during the dental treatment of haemophilic pacients}

- fillings, scalling, root canal and all cosmetic and preventative care can be carried out routinely on patients with mild bleeding disorders

- however, care should be taken with the soft tissues, especially the use of impression trays, aspirators and $\mathrm{x}$-ray films in the floor of the mouth

- for people with mild or moderate haemophilia, non-surgical dental treatment can be carried out under antifibrinolytic cover, but a hematologist must be consulted before other procedures are done (Table 4)

- for people with mild haemophilia A (with factor VIII > 10\%) and most people with VWD (type 1), scaling and some minor surgery may be possible under desmopressin (DDAVP) cover; however, DDAVP is not effective in haemophilia $B$ (even mild cases) as it does not boost factor IX levels

- tranexamic acid used tropically significantly reduces bleeding following dental treatment; a mouthrinse of $10 \mathrm{ml}$ of a $5 \%$ solution used for two minutes, four times daily for seven days, is recommended.; it may be used in combination with oral tranexamic acid tablets for up to five days

- the doctor may recommend antibiotics before any invasive dental procedures if the patient has a joint replaced or venous access device

- screening for factor VIII inhibitors is necessary before any invasive procedure, including dental work; for patients with inhibitors, treatment with recombinant factor VIla or FEIBA may be required

- blood-borne infections should not influence access to dental care

- HIV has been an issue in the haemophilia community; it can cause mouth problems, particularly infections such as candidosis and ulcers; treatment can be complicated by thrombocytopenia, which can worsen the bleeding tendency

- hepatitis $C$ is extremely common in people with haemophilia, can be associated with a prolonged prothrombin time or INR (International Normalized Ratio) and thrombocytopenia; in such cases, bleeding cannot be prevented with factor VIII (or IX); fresh frozen plasma may be required.

TABLE 4. Alternative or adjunctive hemostatic therapy

\begin{tabular}{|l|l|l|}
\hline Medication & Dosage & Route \\
\hline Desmopressin (DDAVP) & $0,3 \mu \mathrm{mg} / \mathrm{kg}$ & $\mathrm{IV}, \mathrm{SC}$ \\
\hline Tranexamic acid & $25 \mathrm{mg} / \mathrm{kg} \times 3 / \mathrm{d}$ & $\mathrm{IV}$, oral, topic \\
\hline $\begin{array}{l}\text { Epsilon-amino-caproic } \\
\text { acid (EACA) }\end{array}$ & $50 \mathrm{mg} / \mathrm{kg} \times 4 / \mathrm{d}$ & IV, oral, topic \\
\hline
\end{tabular}

\section{Areas of concerns}

- extractions and surgery

- gingival surgery/ deep root planning and

- implant placement, all pose a bleeding risk, even in patients with mild haemophilia; so, it is essential that these procedures are carried out with the necessary pre-operative special measures such as factor replacement, DDAVP or Cyclokapron tablets

- deep injections, surgical procedures particularly those involving bone (extractions, dental implants) and regional local anesthetic blocks should be avoided, where possible, as they may start a bleeding crisis

- local use of fibrin glue and swish-andswallow rinses of tranexamic acid before and after dental extractions are safe and costeffective methods to help control bleeding

- after tooth extraction, a diet of cool liquid and minced solids should be followed for five to ten days

- any swelling, difficulty swallowing or hoarseness must always be reported to the doctor immediately

- people with hemophilia with injuries to the head and neck are at risk from bleeding into the brain or neck and should, therefore, be given factor replacement

\section{Local anaesthetic and analgesia}

- infiltration injections pose no risk to patients with haemophilia; however, they should be administered slowly

- Inferior Dental Blocks (ID Blocks) may potentially cause a muscle bleed which might compromise the airway; these should be avoided where possible 
- alternative techniques such as buccal infiltrations or intra-ligamentory routes should be considered for anesthesia of molar teeth

- if an ID Block is unavoidable, patients with less than $30 \%$ factor levels will require factor replacement prior to its administration

- recommending pain relief, NSAID's and aspirin will aggravate a bleeding condition, so paracetamol or codeine based products are more appropriate

- we can use in case of pain stepwise paracetamol, acetaminophen, and in severe cases codeine or tramadol; they are safer alternative analgesics

- bleeding can be aggravated by analgesics such as aspirin and other nonsteroidal anti-inflammatory drugs such as indomethacin.

\section{CONCLUSIONS}

People with haemophilia or congenital bleeding tendencies are a priority group for dental and oral health care, since bleeding after dental treatment may cause severe or even fatal complications.

Maintenance of a healthy mouth and prevention of dental problems is of great importance, not only to quality of life and nutrition, but also to avoid the dangers of surgery.

\section{Acknowledgement}

All authors have same contribution for this article.

\section{REFERENCES}

1. WFH: Guidelines for the management of hemophilia - 2nd edition. Prepared by the Treatment Guidelines Working Group, on behalf of the WFH, 2013

2. Colvin BT, on behalf of EAHAD: European Principles of Haemophilia Care, 2008, Haemophilia, 14,361-374

3. Mealey BL. Influence of periodontal infections on systemic health. Periodontology 2000, 21: 197-209

4. Coppola A, Morfini M, Cimino E, Tufano A, Cerbone A, Di Minno G. Current and evolving features in the clinical management of haemophilia. Blood Transfusion, 2014,12 Suppl.3,554-562
5. Shilpa Padar Shastry, Rachna Kaul, Dilshad Umar. Hemophilia A: Dental considerations and management. www. ncbi.nlm.nih.gov/pmc.articles/ PMC4304051

6. Rodriques LV, Moreira MS, Ouveira CR, Valenca AN. Tooth loss and associated factors in patients with coagulopathies in the state of Paraiba, Brazil. Rev. Bras. Hematol. Hemother, 2013, 35, 5

7. Brewer A, Correa ME. Guidelines for Dental Treatment of Patients with Inherited Bleeding Disorders. WFH: „Treatment of Hemophilia" 2006, 40; 1-12
8. Anderson JA, Brewer A, Creagh D: Guidance on the dental management of patients with haemophilia and congenital bleeding disorders. Brit..Dent. J, 2013, Nov.2, 215 (10),497-504

9. Cervero JA, Poveda RR, Bagan JV, Soriano JY. Dental treatment of patients with coagulation factors alterations: An update. Med Oral Patol Oral Cir Bucal 2007; 12:E380-7 